\title{
De piedras a flores: experiencia de participación infantil a través del arte en un tianguis del Estado de México
}

Freya Castro Pimentel ${ }^{1}$

Universidad Autónoma Metropolitana - Unidad Xochimilco

\begin{abstract}
Artículo científico
Material original autorizado para su primera publicación en el Journal de Ciencias Sociales, Revista Académica de la Facultad de Ciencias Sociales de la Universidad de Palermo.
\end{abstract}

Recepción: 12-03-2018

\section{Aceptación: 26-08-2018}

Resumen: Este artículo científico describe un proceso de investigación sobre acciónparticipativa enfocada a la participación infantil como derecho inherente a todo ser humano, dentro de marcos de derechos nacionales e internacionales, con incidencia en un tianguis como espacio público- del municipio de Nezahualcóyotl en el Estado de México durante 2014 y 2015. Se procuró fomentar una participación dirigida por niños en todas las etapas de la intervención. Lo que inició como un proyecto de participación de niños, niñas y adolescentes para la creación de un Consejo de Participación Ciudadana Infantil, al ser estos últimos sujetos de derechos, terminó siendo una muestra de la capacidad de agencia de los niños, a través del arte, llevando lo privado a lo público y visibilizando su existencia en un espacio dominado por adultos. Es el recuento de los cambios que puede generar la participación de los niños en los ámbitos sociales e individuales y los alcances de la misma investigación y de la participación infantil. Este artículo es también la narración de los aprendizajes que arrojó la práctica de trabajar en un marco participativo con niños en una zona altamente violenta y peligrosa y es, también, una propuesta para seguir replanteando los conceptos de participación infantil, democracia, poder y agencia.

Palabras clave: participación infantil; investigación acción participativa; espacio público; agencia infantil.

\footnotetext{
${ }^{1}$ Licenciada en Psicología por la Universidad Autónoma Metropolitana - Xochimilco. Área de concentración: Educativa. Enseñanza-aprendizaje de lenguas extranjeras y educación musical. Estudiante de MBA por la University of the People. Correo electrónico: freyacastro@gmail.com
} 


\title{
From Stones to Flowers: Experience of Children's participation Through Art in a Tianguis of the State of Mexico
}

\begin{abstract}
This scientific article describes a process of a participatory action research focused on child participation as an inherent right to every human being, in an international and national rights framework, with impact on a street market - as a public space- in the municipality of Nezahualcóyotl in the State of Mexico in 2014 and 2015, encouraging a childled participation in every stage of the intervention. What started as a project of children participation for the creation of a Children's Civic Participatory Council as they are subjects of rights, ended up being an example of the children's capacity of agency, through art, bringing out the private to the public, making their existence visible in a space dominated by adults. It is the recount of the changes generated by children's participation on social and individual domains and the scope of this research and of children's participation. This article is also the account of what was learnt by the practice of working in a participatory frame with children in a highly violent and dangerous zone, and it is also a proposal to keep reconsidering the concepts of children participation, democracy, power and agency.
\end{abstract}

Key words: child participation; participatory action research; public space; child agency.

\section{Introducción}

Dentro del marco de la Convención sobre los Derechos de los Niños ratificada por México hace más de 20 años, los derechos a la participación y a la protección se erigen como pilares del desarrollo de los niños concebidos como sujetos de derecho, sujetos de cultura y actuales ciudadanos.

La colonia Impulsora, localizada en el municipio de Nezahualcóyotl dentro del Estado de México, presenta graves problemas de inseguridad y manejo del espacio público, a la vez que implementa programas de bienestar social orientados principalmente a la infraestructura urbana y destinados únicamente a la población adulta.

Es por todo esto que se creyó urgente y necesario el dar lugar a las voces de niñas, niños y adolescentes que viven en este espacio, teniendo como eje la elaboración de un diseño de investigación e intervención coherente con el resultado que queremos obtener: un Consejo de Participación Ciudadana Infantil diseñado, creado y evaluado por ellos y para ellos dentro del marco de una investigación final de la universidad. En este proceso surgen retos y cuestionamientos acerca de la agencia y participación infantiles.

\section{Perspectiva teórica}




\section{Un marco de derechos}

En 1959, la Asamblea General de las Naciones Unidas aprobó la Declaración de los Derechos del Niño, texto que luego dio paso a los siguientes borradores que formarían la Convención sobre los Derechos del Niño (CDN) treinta años más tarde, siendo el único tratado de derechos humanos internacional con casi ratificación universal (193 ratificaciones). Así pues, se concretó un marco sólido para los derechos humanos a nivel mundial que abarcaba la totalidad de estos (económicos, sociales, culturales, civiles y políticos) (Lee, 2007, p. 11).

Con ello, niñas, niños y adolescentes pasaban a ser sujetos de derechos. A nivel estatal, las naciones adscritas se comprometieron a hacer valer los derechos de los niños y adquirieron tres tipos de obligaciones: la obligación de respetar (obligación negativa), de cumplir (obligación positiva) ${ }^{2}$, y la obligación de proteger (al individuo de la interferencia de terceros o de otros grupos de individuos).

México, al ser uno de los Estados Partes, se compromete a respetar "los derechos enunciados en la presente Convención y [asegurará] su aplicación a cada niño [...]."3 La creación de la Ley General de los Derechos de Niñas, Niños y Adolescentes (LGDNNA) en 2014 se inserta en este marco, y tiene por objetivo: reconocer a estos últimos como titulares de derechos; garantizar el pleno ejercicio, respeto, protección y promoción de sus derechos; y crear el Sistema Nacional de Protección Integral de los Derechos de Niñas, Niños y Adolescentes. ${ }^{4}$

\section{Niñas, niños y adolescentes como actores sociales y plenamente} participativos

A partir de 1996, el Comité de los Derechos del Niño presentó el término de General Principles (Principios rectores o principios fundamentales en español), señalados en los artículos 2, 3, 6 y 12 de la Convención: principio de no discriminación; principio de observar siempre el interés superior del niño; principio del derecho a la vida, la supervivencia y el desarrollo y principio de participación y de ser escuchado.

A efectos de la investigación, nos centramos en el principio de participación. El artículo 12 es, junto con el 13 y el 15, el pilar de la participación infantil, tanto para su desarrollo como para su implementación (Doek, 2007, p. 37). Según el artículo 12 de la CDN, la participación es el derecho de todo niño, niña, adolescente (NNA) de formarse una opinión,

\footnotetext{
2 Artículo 4.1

${ }^{3}$ Convención sobre los derechos del niño, Artículo 2.1

${ }^{4}$ Artículo primero de la Ley General de los Derechos de Niñas, Niños y Adolescentes.
} 
expresar esa opinión y ser tomado seriamente en cuenta en todos los asuntos que le pueda afectar.

La misma Comisión de los Derechos del Niño establece que el derecho a la participación aplica a absolutamente todos los NNA, de bebés a adolescentes, y es obligación de los adultos hallar maneras de escucharlos. Los Estados Partes deben garantizar la escucha de acuerdo con la edad y al desarrollo del niño.

El derecho a la participación implica también el derecho a ser oído y a la garantía de estar en un espacio y tiempo seguros para hacerlo. Los adultos deben proporcionar la información necesaria acerca de todos los asuntos que importen a los niños. Los adultos deben brindar tiempo. Los tiempos de los niños son distintos a los tiempos de los adultos. El derecho a la participación es, entonces, el derecho de los NNA a:

- formarse una opinión acerca de todos los asuntos que les pudieran afectar, que les conciernen;

- expresarla en un entorno seguro con suficiente tiempo, información y confianza;

- de manera voluntaria;

- y que esta opinión o expresión sea tomada en cuenta.

Teniendo todo lo anterior en mente, los espacios para niños deberían ser diseñados, imaginados, deseados por los niños. De esta manera -y solo así, serían espacios de niños.

\section{De menores a Niños, Niñas y Adolescentes:}

¿Qué es un niño? Por muchos años, los niños fueron definidos dentro del marco legal como menores de edad: alguien menor a 18 años. Sin embargo, el término menor impregnó también otras esferas sociales y conceptuales. La CDN es el cisma entre el antiguo paradigma de los "menores de edad" y por lo tanto "incapacitados", y el de NNA. Estos últimos son, según González Contró (2011), destinatarios de dicha Convención y por ende sujetos de derecho. Implica, de igual manera, pasar de la situación irregular a la protección integral, y en especial hacia una autonomía progresiva donde el desarrollo de habilidades y la capacidad del ejercicio autónomo de los derechos son primordiales. Por lo tanto, no se espera el desarrollo total de NNA para que puedan entonces ser acreedores de derechos, sino que gozan de los mismos desde los 0 años y cada etapa del desarrollo representa una totalidad.

Los niños son, pues, sujetos de derechos que deben beneficiarse de una protección integral. La protección ha sido un tema abordado desde distintos ángulos para debatir y cuestionar el alcance y los riesgos de la participación infantil en esferas más públicas y, por lo tanto, más políticas. Según Breviglieri (2014, p. 100), Arendt diría que los niños no cuentan aún con las capacidades para las exigencias del dominio público y que requieren ante todo 
de una protección más que de una participación en el espacio público. Si bien podríamos precisar que un contexto de autoritarismo es el que dio luz a este pensamiento, no deja de ser relevante que se asocie a los niños con esta necesidad imperiosa de protección y contraponerla a la voluntad de participación en situaciones que superen la dicotomía privado/público. Wyness et al (2004, p. 88), por su parte, distinguen dos tipos de derechos de NNA: los que denominan de bienestar y los que involucran la libre (o auto) determinación del niño. ${ }^{5}$ Los primeros tienen que ver con el rol activo de los adultos en propiciar, garantizar y proteger esos derechos ligados al bienestar infantil. Los segundos giran más entorno a la capacidad de decidir de los niños acerca de sus propias necesidades y voluntades, apelando a distintos grados de agencia y autonomía. ¿Cómo lidiar entonces con situaciones en las que la libre determinación del niño se antepone a los derechos de bienestar que tienen que facilitar los adultos? ${ }^{6}$ Desarrollaremos este tema más adelante.

\section{Niveles de participación}

Participar mejora la autoestima, facilita el desarrollo de habilidades cognitivas y sociales (Lansdown, 2011, p. 5). Las aspiraciones de los niños son más altas: cada niño, niña o adolescente incide de acuerdo con sus voluntades y capacidades. La participación infantil también involucra la esfera familiar y comunitaria; propicia la escucha de todos los participantes. De igual manera, protege a NNA de maltrato, abuso y violencia. Un niño que ha aprendido a escuchar y ser escuchado, que ha aprendido el poder y la importancia de la palabra, sabrá comunicar cuando se sienta en peligro, le será más fácil ubicar o al menos señalar ante la autoridad responsable y más conveniente si sus derechos se ven violentados.

Necesitamos también contemplar el amplio espectro de la participación. ¿Cómo podrían NNA apropiarse de su espacio, incidir en él? La participación también se define según la actuación e implicación de los niños en el tema en cuestión. Lansdown (2005) detalla los posibles tipos de participación de NNA, según el nivel:

1) iniciando con el proceso consultivo (propiciado por adultos conscientes de que los niños poseen sus propias opiniones);

2) contemplando en todo momento el proceso participativo (iniciado por adultos y compartido por y con los niños);

\footnotetext{
${ }^{5}$ Welfare rights y self-determination rights.

${ }^{6}$ Los autores ejemplifican la situación mencionando el derecho a la educación (sabiendo que maestros y adultos pueden saber que esto es en beneficio del niño) y yuxtaponiéndolo a la posibilidad de que el niño podría escoger no ir.
} 
3) para lograr el autónomo (donde son los niños quienes definen los temas de interés y las formas de llevar a cabo el proyecto, con la participación "facilitadora" de los adultos).

El objetivo sería alcanzar el octavo peldaño en la escalera de participación propuesta por Roger Hart (1993). En este, las actividades llevadas a cabo son "iniciadas por niños [y las] decisiones [son] compartidas con adultos". Se llega así a una "participación genuina" puesto que hay una superación del estado de manipulación, decoración y/o participación simbólica. Dicho con otras palabras, la participación dirigida por NNA equivale a crear un espacio donde ellos mismos puedan identificar los temas que crean trascendentes e importantes a tratar y comenzar a vislumbrar las posibles soluciones para también comenzar a organizarse.

Podemos empezar a entrever las complicaciones y dificultades que conlleva pensar en una participación autónoma total de NNA que pudiera cuestionar los principios de protección de parte de los adultos, por ejemplo, y aún más en un espacio manejado, diseñado y dominado por ellos: el espacio público.

\section{La participación en un espacio público}

El espacio público es aquél donde cualquier persona, dentro del contexto de la ciudad, tiene derecho a estar y circular libremente. Podemos definir el espacio público a distintos niveles. Tanto a nivel físico como a nivel social, según los usos (culturales, económicos, políticos, de movilidad) que se le den (Pourailly, 2015, pp.14-15). A nivel social, es un espacio que se define por oposición a lo privado, donde se condensan los encuentros y los intercambios y hay una ebullición de procesos de identificación facilitados a través del anonimato. Según Páramo (2010) citado en Pourailly (2015, pp. 14-15): "Particularmente el espacio público ha sido el escenario por excelencia de aprendizaje y exhibición de las prácticas sociales que identifican y cohesionan los grupos culturales".

Aunque Arendt preconice la protección de los niños y niñas de la vida política, le otorga al espacio público un lugar imprescindible dentro del desarrollo pleno e íntegro de cualquier ser humano: "como un espacio de relaciones entre individuos, quienes, a través del discurso y sus acciones, contribuyen a modelar el mundo común como un horizonte de entendimiento y encuentro ciudadanos" (Sahuí, 2002, p. 261), teniendo como ejes la "pluralidad, igualdad y libertad humanas" (Sahuí, 2002, p. 263). Pero lo público no puede estar separado de lo político y el derecho al espacio público es intrínsecamente un derecho a la ciudadanía. 
El derecho a la ciudad no es tan solo el derecho a usarla, sino también el derecho a interpretarla, a identificarnos con ella, a apropiarnos (aunque sea simbólicamente) de sus espacios, a "privatizar" lo público y a "publicitar" lo privado, y ello de manera fluida, espontánea, creativa (Valera, 1999, p.10).

Si los niños son ciudadanos son entonces también entes políticos. Abordar la participación de la niñez requiere entonces cuestionar los conceptos mismos de política y niñez requiere entonces cuestionar los conceptos mismos de política, democracia, poder, agencia y capacidades.

\section{Niñas, niños y adolescentes en la política}

Por un lado, están los que afirman que los niños no cuentan con las capacidades para participar en la vida política de un país. No son aptos o no están capacitados. El mundo de la política sería un mundo reservado para personas capaces, personas adultas. Seguiríamos hablando de menores versus mayores, de incapacidad versus capacidad. Wall (2011, p. 91) menciona a Rawls, quien describe la ciudadanía política como el ejercicio de 'la plena autonomía' cuando se es capaz de explicar por qué y por quién se vota (principios y políticas), lo que lo lleva a asumir, sin argumento, que el término 'ciudadanos iguales' refiere solo a 'personas adultas en la sociedad'. Pero añade que esta habilidad de actuar políticamente según las propias ideas y principios no está ausente en los niños.

Por otro lado, están los que señalan que los niños, conforme a su edad, tienen las capacidades necesarias para intervenir en la vida política, aunque bajo la guía y protección de un adulto. Como mencionábamos anteriormente, Hart mismo contempla que haya que sortear los riesgos de la manipulación adulta hacia los niños, por ejemplo. NNA serían capaces de decidir sobre ciertas cosas y requerirían capacitación y protección sobre tantas otras. Algunos otros plantean que ciertas consultas, parlamentos y simulacros son una forma de educación en la política, pero nada más. Según Wyness et al (2004, p. 84) los niños son entonces aprendices de ciudadanos en vez de ser miembros plenos de la sociedad y los autores se cuestionan si acaso se estuvieran educando en el deber político sin proporcionarles necesariamente los beneficios del mismo, beneficios que solo se obtendrían al llegar a la adultez.

Pero, entonces, ¿podemos hablar de democracia cuando una gran parte del demos no está propiamente representada ni tiene capacidad real para poder inferir en lo que les concierne? Para que esto sea posible, la participación es indudablemente una condición. "EI considerar a los niños con capacidades y habilidades para participar en todos los aspectos de la vida implica que [...] dentro de esta mirada, todos los ciudadanos tienen la obligación 
de constituirse en defensores y garantes de niños, niñas y adolescentes" (Corona y Gáal, 2009, p. 7). Participar es hacer un lugar y un espacio; tomar parte. La participación no es de uno solo o de un solo sector; la participación es de quienes quieran, de quienes deban y de quienes estén. Pero ¿de qué manera garantizamos la escucha de niños y niños cuando pasa por filtros adultos? ¿Cómo podemos hablar de capacidad de agencia total y no de participación simbólica?

\section{Agencia y poder infantiles}

¿Por qué la participación, por qué la agencia? Como dice Ricœur en Breviglieri (2014, p. 116) nuestra primera entrada en el terreno del derecho fue con un grito de injusticia, de indignación que, si bien de adultos adquiere otros tenores, existió desde niños. Desde el momento en el que el niño se pregunta qué le gustaría cambiar, en qué le gustaría incidir y cómo le gustaría participar, se está gestando la capacidad de agencia. Iniciar una acción intencionada para poder lograr eso que ya se estableció en la mente del niño, eso es agencia. Poder incidir en sus espacios, hacerlos suyos; poder incidir en el mundo mostrando de qué forma lo ven. Algunos de los bemoles de la agencia infantil tienen que ver con su alcance. Cuando NNA perciben estos mecanismos de participación infantil como superficiales, condescendientes y marginales, tienden a desistir y se ven después alienados de todo el sistema (Wyness et al, 2004, p. 87). La capacidad de actuar no siempre va de la mano con la capacidad de incidir y de generar un cambio. La ciudadanía o la agencia política no serían entonces lo mismo que el poder político (Wall, 2011, p. 90). No obstante, existen ejemplos del ejercicio directo de poder político por parte de NNA: parlamentos infantiles que han cambiado políticas educativas (India) o incluso inciden en cierta parte del presupuesto de la ciudad (Brasil) (Wall, 2011, p. 88). ¿En qué radica entonces la diferencia entre una agencia limitada y una total?

Wall (2011, p. 91) diría que el problema radica en quién tiene el poder de definir qué significa la agencia política y de controlar sus límites bastante amorfos y que estos mismos conceptos de agencia, poder y democracia son conceptos con todo un sesgo adultocéntrico. El modelo de agencia que comúnmente se conoce viene de constructos adultos cuando debería retar y cuestionar estos últimos (Wall, 2011, p. 91). Pensemos unos segundos en la complejidad del marco de derechos de la Convención y de la escalera de participación de Hart. Apelando el objetivo del último peldaño, ¿los derechos de los niños no estarían siendo menos directos porque son redactados dentro de un programa estructurado y llevado a cabo por, en su mayoría, adultos? 


\section{Repensando la agencia y la democracia}

Para una inclusión plena de NNA en procesos democráticos, valdría la pena pensar en un concepto mucho más vasto del sujeto político, así como de su terreno o campo de acción. Wall (2011, p. 87) precisa que no se trata solo de una extensión de los privilegios de los adultos a los niños, sino de una reestructuración de las normas sociales como respuesta a las experiencias de los niños. La problemática se encuentra en la relación que se establece entre la expresión "participación infantil”, la escucha y la acción, es decir: cómo respondemos -como adultos-, a esa participación de niños, niñas y adolescentes ya que ellos, en un mundo adultocéntrico con políticas y mecanismos creados y llevados a cabo por adultos a su vez, están siempre en desventaja.

Hagamos primero un recuento de las dificultades mencionadas hasta ahora acerca de la participación infantil. Están los cuestionamientos acerca de la capacidad de los niños para entender mecanismos de la política y de la participación en esferas públicas. A esto se le agrega la gran responsabilidad que puede ser para un niño cargar con el peso del poder (Arendt en Breviglieri, 2014). En otros casos, si se da la participación, se tiene que velar a que esta se mantenga alejada de las posibles manipulaciones adultas o que solo sea una participación simbólica (Hart, 1993; Wyness et al, 2004). Cuando finalmente se llega a una participación auténtica, donde los grados de autonomía y agencia de los niños son los más elevados, los derechos de autodeterminación pueden desbancar a los de bienestar, ya que los niños pueden estar en posición de denegar las definiciones adultas de su 'mejor interés' (Wyness et al, 2004, p. 88).

Los derechos de NNA junto con la participación infantil y su agencia han propulsado grandes avances. Sin embargo, observar sus alcances actuales y sus limitantes puede también favorecer su desarrollo. Una de ellas parece ser, por un lado, que los conceptos siguen estando insertos en un modelo adultocéntrico. Por otro, la respuesta de los adultos a la participación infantil es también crucial: son quienes tienen el poder de definir lo que es la agencia y sus límites. Visto desde este punto, son quienes también tienen mayor experiencia, educación, práctica y recursos, lo cual dejaría a NNA en desventaja en un diálogo supuestamente igualitario. Wall (2011) presenta la noción de respuesta a la diferencia ${ }^{7}$ en donde las diferencias, en vez de ser desventajas, serían el eje central del poder. Para él, si ciudadanía significa luchar entre las diferencias, los niños automáticamente están en desventaja por su relativa dependencia de otros para ejercer poder en su nombre. Se necesita entonces un modelo en donde los actores políticos puedan estar incluidos interdependientemente y empoderados diferentemente al mismo tiempo (2011, p. 94). Según

\footnotetext{
${ }^{7}$ Difference-responsiveness.
} 
Ricoeur en Wall, la base de las relaciones sociales es la atribución al otro de la capacidad de responder. La respuesta a la diferencia sería la responsabilidad de responder a las diferencias: "a capacity to enable differences of perspective to make a difference to the existing social imagination" (Wall, 2011, p. 95). Por ejemplo, un niño sin acceso a vacunas no es meramente diferente, sino que crea la obligación de su comunidad de responder a esa diferencia. De esta manera, los niños alcanzarían un estatus más elevado, convirtiéndose entonces en la prueba más importante de la democracia, al ser los que podrían apelar más a la capacidad de respuesta/acción de la totalidad democrática (2011, p. 95).

\section{Contexto: ubicación espaciotemporal}

La intervención se realizó de junio de 2014 a abril de 2015 en México, en el municipio de Nezahualcóyotl ubicado en el Estado de México en el tianguis de la colonia Impulsora, colonia caracterizada por problemas sociales complejos y una ingobernabilidad provocada, aparentemente, por la ubicación geográfica (colonia limítrofe, colindante con otros municipios del Estado y delegaciones de la Ciudad de México). Los espacios públicos han sufrido un proceso de enajenación a causa del descuido, de la falta de planificación y de la inseguridad; los espacios dedicados al esparcimiento y a la recreación son prácticamente inexistentes; los espacios dedicados a la infancia son aun menores y los hechos por ella permanecen impensables.

La mayoría de los espacios públicos de este sector están estrechamente ligados al comercio. Una de las sedes más importantes de ebullición social, cultural, económica y política es el tianguis.

Existe una dimensión importante a considerar para la lectura y el análisis de toda esta investigación y de la intervención: la de la violencia, que no hay que deslindar de otra categoría analítica como lo es la pobreza. La colonia Impulsora ha sido señalada como una de las colonias con índices delictivos más altos de uno de los municipios más violentos de uno de los estados más problemáticos del país. Dentro del Programa de Prevención Social de la Violencia y la Delincuencia (llevado a cabo desde 2014), parte del presupuesto está destinado a zona por ser uno de los focos rojos nivel nacional ${ }^{9}$.

Por todo lo anterior -la inseguridad, los pocos espacios de convivencia y la importancia central que tiene el tianguis en la vida de la colonia-, se optó por comenzar la

\footnotetext{
${ }^{8}$ Una capacidad de posibilitar diferencias de perspectiva para cambiar) el imaginario social existente. (La traducción es nuestra.)

${ }^{9}$ Se puede encontrar el comunicado oficial del Gobierno de Nezahualcóyotl en http://www.ipomex.org.mx/ipo/archivos/downloadAttach/313956.web;jsessionid=FE7590BCE5EF31B8D96FC20 A4A5C0563
} 
investigación y la incidencia en el tianguis. El tianguis de la Impulsora es bastante grande (aproximadamente 1 kilómetro de principio a fin) y se instala cada domingo en un horario de 7 a 17 horas.

\section{Método}

Nuestro objetivo general era diseñar, ejecutar y evaluar una propuesta de trabajo a partir del arte como lenguaje de expresión infantil, por medio de la inmersión en un tianguis para la creación de un consejo de participación ciudadana infantil. Se quería el consejo de participación ciudadana infantil como expresión máxima de la participación y agencia de NNA. De principio a fin procuramos que nuestro diseño metodológico fuera congruente con nuestros objetivos. Se optó entonces por una investigación de corte esencialmente cualitativo y procurando la participación: una investigación acción-participativa (IAP). Siguiendo a Contreras, podemos decir que

Hablamos entonces de una acción sistemática de fases sucesivas encaminadas a perfeccionar los mecanismos de un grupo para alcanzar de mejor forma los objetivos que se ha planteado, a partir de ejercicios de toma de decisión. La base de dicho proceso es el involucramiento de las personas en dinámicas de decisión colectiva en función de sus intereses (2002, p. 13).

La IAP y los proyectos o investigaciones que buscan la participación de NNA tienen numerosos puntos en común. Ambas centran sus objetivos en la escucha de la comunidad, en vías de una mejora de cualquier situación que la comunidad plantee. "Es un instrumento de acción" para la misma (Contreras, 2002, p. 11). Ambas saben que la comunidad tiene lo que se requiere para ella misma identificar los puntos de cambio. Ambas requieren y preponderan la activa participación constante de los involucrados, de la comunidad.

Conforme pasaron las semanas, los niños fueron tomando las riendas del taller artístico, pasando así a una investigación de participación infantil. El otro punto para distinguir está relacionado con los altos estándares de ética que debíamos manejar en todo momento, tratándose de NNA, y abarcar desde el consentimiento informado, la confidencialidad, el uso de pseudónimos, así como contemplar y tomar en cuenta las expectativas de los niños, sin perder de vista el alcance y la posibilidad.

El diseño metodológico tomó entonces tanto de las IAP como de los manuales ${ }^{10} \mathrm{y}$ recomendaciones para trabajar la participación infantil. Se diseñó lo siguiente en los inicios:

\footnotetext{
${ }^{10}$ A toolkit for monitoring and evaluating children's participation: https://www.unicef.org/adolescence/files/ME toolkit booklet 4-2014.pdf
} 
1. Identificación del proyecto y propuesta de los objetivos: identificación de la falta de un consejo de participación infantil. Parecía un buen punto de partida así que el objetivo fue diseñar uno con la participación de NNA de la colonia.

2. Diseño de un dispositivo a través del cual poder recabar datos y elaborar un diagnóstico. Establecer en el tianguis un puesto de actividades artísticas (dibujo, creación de instrumentos musicales, elaboración de figuras de pasta, propuesta de pequeña orquesta) abierto a todo público (aunque enfocado a NNA), completamente gratuito, cada domingo. Esto nos permitiría tanto relacionarnos con el espacio (público) como con sus actores principales desde una perspectiva etnográfica.

3. Los temas que salieran en las actividades artísticas del tianguis se discutirían con los niños, creando un grupo focal. Se seguiría usando el material artístico como lenguaje común además del habla.

4. A partir del grupo focal, se elaboraría en conjunto con los NNA un diseño de intervención en el espacio público como primera intervención.

5. Se formalizaría el proyecto ante las instancias necesarias (autoridades gubernamentales) para que esto diera pie a la constitución de un Consejo de Participación Ciudadana Infantil de la colonia Impulsora.

Asimismo, desde los inicios, se contemplaba la retroalimentación al término de cada etapa del diseño, lo cual nos permitió darnos cuenta de que los niños que frecuentaban nuestro puesto eran niños hijos de los trabajadores del tianguis o familiares de estos, en su mayoría. Decidimos entonces adaptar, junto con ellos, el nombre del consejo: Consejo de Participación Ciudadana de Niñas y Niños del Tianguis que, a su vez, terminó siendo "Niños del Tianguis" -término propuesto por ellos mismos.

La esencia de las IAP y de los proyectos que fomentan la participación infantil es tener un diseño bastante flexible y, al seguir un rigor metodológico importante, pudimos darnos cuenta de que los niños, ya en el puesto del tianguis, estaban creando su propio consejo y elaborando sus propias propuestas generadoras de cambio. Nuestro objetivo principal de crear el consejo de manera formal ante una instancia gubernamental no respondía a las necesidades más urgentes de los niños: hacerlos visibles, como lo veremos más adelante.

La participación de los niños estaba contemplada en los pasos 2, 3 y 4 así como en las retroalimentaciones y siempre se contempló una participación total, aunque no siempre se obtuvo. 


\section{Desarrollo del proyecto y resultados}

En este tipo de investigación, el desarrollo y la modificación o los ajustes del diseño e incluso de las propuestas forman parte de los resultados. Después de haberla terminado, pudimos saber que el promedio de niños y niñas que participaron constantemente fue de 5 , con un máximo de 15 en algún domingo. Fueron niñas y niños por igual, de entre 3 a 12 años. A continuación, se presenta el desarrollo del proyecto, apuntando el tipo de actividades realizadas y el tipo de participación de los niños.

Semanas 1-2: instalación de nuestro "puesto": un tapete y una sombrilla con material para elaboración artística (lápices, colores, acuarelas, hojas, plumones) además de una señalización (hecha a base de cartulinas) para indicar que el puesto era para todos y podían usar los materiales libre y gratuitamente. Esto permitió introducirnos en el campo. Hubo expresiones de extrañamiento por parte de la gente, pero fueron los niños quienes dieron paso a establecer poco a poco lazos de confianza. Una de las niñas, hija de una comerciante del tianguis cuyo puesto estaba a escasos metros del nuestro, de 5 años, fue quien comenzó a convocar más niños. La segunda semana se colocó material para la elaboración de instrumentos musicales (botellas, semillas, cascabeles...). Participación de NNA: originalmente, no había demanda de NNA, pues no hubo un llamado por parte de los niños hacia nosotros. La inquietud surgió de nuestra observación y análisis teórico como investigadores. Conforme transcurría el tiempo, los niños fueron participando cada vez más al invitar a semejantes por iniciativa propia. Las actividades seguían siendo propuestas por los investigadores.

Semana 3: Surgió la propuesta de jugar por parte de los niños. Surge la alternancia entre el dibujo y el juego. Participación de NNA: Actividad propuesta por ellos; organización llevada a cabo por ellos.

A partir de la semana 4: los niños que asistían regularmente comenzaron a invitar más enfáticamente a cada niño que veían pasar, y explicar la gratuidad y las posibilidades con el material. Participación de NNA: Iniciativa propia de NNA para la invitación; diálogo entablado entre pares para invitarlos a participar; ocasionalmente, diálogo de niño a adulto para 'convencer'. Comienza a conformarse un grupo regular: comparten anécdotas y experiencias.

Comenzábamos a formar parte de la comunidad puesto que los mismos comerciantes nos reservaban nuestro lugar y esperaban vernos cada semana. Los asiduos del tianguis ya nos ubicaban y planeaban sus trayectos a través del tianguis para dejar a los niños en el puesto. Iniciaron también las retribuciones: a pesar de que siempre enfatizamos que no se 
pedía nada a cambio (ni en dinero, ni en especie), varios quisieron aportar al mismo puesto colores, crayolas, lápices.

7 de diciembre de 2014: formalización del Consejo. Compartimos la propuesta del Consejo. Usamos las palabras "hacer un grupo para hablar de lo que les gusta, lo que no y lo que quisieran cambiar". Hasta ese momento no existía ninguna formalidad. No se había querido hacer antes por la importancia de la inmersión en el campo (que se cercioraran de la constancia y el compromiso y por lo tanto hubiera algo de confianza). Hicimos entonces un escrito -consentimiento informado- incluyendo datos personales, así como objetivos del proyecto que se entregó a cada uno de los interesados. Buscábamos un espacio fijo, un lugar visible, seguro y que pudiera ser constante (los comerciantes nos apartaban lugar, mas no era fijo). Al momento de comentarlo con los padres o familiares de los niños que frecuentaban nuestro puesto, varios sugirieron locales que tal vez podríamos conseguir a bajo precio o incluso pedir espacio en infraestructuras gubernamentales en desuso. Sin embargo, eso se vislumbraba a largo plazo. Optamos entonces por abrir un espacio a dos cuadras del tianguis, en casa de un familiar de los investigadores. Participación de NNA: Los investigadores iniciamos la propuesta, hicimos el escrito y hablamos con los adultos. No fue sino hasta tiempo después que comprendimos que en esta etapa los niños podían haberse involucrado y quizás llevado a cabo la mayoría o la totalidad de la etapa.

Nos dimos cuenta del error: nuestro grupo focal ya estaba conformado por niños que, en su mayoría eran niños del tianguis. El tianguis era su territorio. Además, al trasladar el puesto que estaba inserto en un espacio público a un espacio cerrado dentro de un espacio privado, estábamos dejando de lado los objetivos y la naturaleza misma del campo con y en el que habíamos empezado. Fue un error que nos permitió definir nuestro espacio de intervención. Decidimos entonces regresar al tianguis. Participación de NNA: de nuevo, al evaluar que bastaba preguntarles si estaban de acuerdo, pensamos que su participación era considerable. Pudimos haberles planteado nuestras inquietudes a la vez que ellos nos planteaban las suyas y elaborar un plan de acción en conjunto.

Semanas de enero de 2015: fuimos entendiendo que la manera de participar de los niños estaba estrechamente ligada a las capacidades y al desarrollo según las edades. Por mucho que quisiéramos plantearles dudas y compartirles lo que nosotros vislumbrábamos como problemático, no hablábamos totalmente el mismo idioma. La edad promedio del grupo era de seis años. Así surgió entonces la idea en conjunto de ser reporteros del tianguis. Una de las maneras más sensatas de ver el tianguis con los ojos de los niños era viéndolo a través de sus miradas. Conseguimos unas cámaras fotográficas desechables y se dieron a la tarea de recorrer el tianguis tomando las fotos que ellos quisieran. Participación de NNA: Nuestras preguntas no eran claras para ellos; la idea de la cámara surgió de nosotros, pero ellos le 
dieron el uso: el de ser reporteros. Decidieron dónde (cómo recorrer el tianguis puesto que ellos lo conocían mejor), cómo (los mayores guiando a los más chicos tomados de la mano, avisando en los cruces de las calles) y para qué (uno de ellos dijo claramente "tomen todo lo que quieran"). Nuestro rol fue de protección y pudimos permanecer en un segundo plano.

Al revelar las fotos, los niños intercambiaron opiniones acerca de ellas. Mostraban orgullo, asombro e interés por sus propias fotos y por la visión de los demás. Pudimos observar que, a pesar de que las fotos se parecían bastante -al menos para nuestra mirada de adultos-, los niños sabían con claridad qué fotos eran de quién. Les preguntamos que qué querían hacer con ellas. La respuesta fue unánime y con tono de obviedad: "ipues mostrarlas!". Decidieron entonces armar una exposición con sus fotos en las siguientes semanas. Nivel de participación: Los investigadores revelamos las fotos. Hubiera sido una gran experiencia hacer un taller de revelado o bien llevarlos a que pidieran sus propios revelados. Los pocos recursos y la falta de espacio no lo permitieron. El proyecto "Exposición: así vemos el tianguis" fue propuesto por ellos. Nos pidieron material (cartulinas) y ayuda para escribir unas cuantas frases explicativas.

Semanas de febrero: hablamos con los niños y les preguntamos si querían hacer algo con el tianguis. La pregunta no era clara. Pasamos entonces a una consulta infantil. En unas hojas, con suficiente espacio para dibujar, pusimos lo siguiente (acompañado de pequeños dibujos para los que todavía no sabían leer): "Para mí, el tianguis es...", "lo que me encanta del tianguis: ...", "lo que no me gusta: ...", lo que me gustaría que tuviera: ...". Al principio, los adultos entrevistamos a dos niños con la ayuda de un micrófono para seguir con la temática de reporteros del tianguis. Acto seguido, los mismos niños entrevistados tomaron el micrófono y entrevistaron a los siguientes. Los niños podían contestar hablando o dibujando o haciendo ambas cosas. Nos dimos cuenta de que el dibujo narrado estaba cargado de significado. También en la expresión artística había que tratar de ver y oír con ojos y oídos de niños. Participación de NNA: no fue una consulta ideada por ellos. Seguíamos pensando, como investigadores, que la problemática estaba en el tianguis y que, por lo tanto, había que cambiar algo del tianguis mismo. La consulta fue después llevada a cabo por ellos.

La consulta arrojó que el tianguis era un espacio de juego, al que le faltaban juegos, flores y árboles. Era también un camino a casa. Y, así como un laberinto o un mapa de metro, era también un espacio peligroso: había que conocerlo muy bien antes de aventurarse en él y "siempre, siempre [había] que tener cuidado". Una niña hizo explícita la violencia al narrar una balacera que había sucedido recientemente y después mencionó un muerto (ella lo describía como "un montón de piedras") afuera de su casa. En los relatos se interpolaban narraciones del tianguis con los de otros lugares, generalmente la casa. Gradualmente, 
fuimos entendiendo que el tianguis era, a veces, una extensión de la casa, de espacios más privados.

Se les preguntó si deseaban compartir esto con la gente y respondieron afirmativamente. Les preguntamos la manera y contestaron: con una obra de teatro, con títeres. En el proceso de elaboración de los títeres (con calcetas, calcetines, botones, colores, listones) vimos -principalmente ellos- que sería difícil realizar una obra de títeres en el espacio y el bullicio el tianguis. Surgió entonces la idea de hacer una campaña. Participación de NNA: si bien la participación aumentaba en autonomía, aún no había propuestas completamente infantiles; eran todavía lanzadas por nosotros, detonando una serie de ideas que se discutían en conjunto. La campaña fue una aportación de ellos, una respuesta a la problemática de la obra de teatro.

Semanas de marzo: para la campaña, idearon poner "imágenes grandotas, como letreros". Realmente no sabíamos, los investigadores, para qué iba a ser la campaña específicamente. Optamos por dejar que los mismos niños, al momento de crear esos "letrerotes" fueran externando lo que esperaban de la campaña. Con unas cajas de cartón (de los mismos puestos del tianguis) y con pinturas crearon sus dibujos a gran escala (más grandes que los que estaban acostumbrados a hacer). Les dijimos que a veces los adultos olvidábamos hablar el lenguaje de los niños -el de los dibujos, así que sería buena idea ponerles unas frases. Los niños nos dictaron las siguientes: "Trátanos con amor. No nos pegues. (Nos duele.)" "No nos peguen, no nos regañen, trátenos bien." "Queremos estar felices." "Queremos que nos lleven a volar al cielo." "Juega con nosotros. "Al peguntarles dónde les pegaban dijeron que en el tianguis, pero también en casa. Entendimos entonces que la incidencia en el espacio público no tenía que ver solo con el mismo espacio público.

Surgió el logo y surgió su nombre: "Los Niños del Tianguis" para efectos de distinción de la campaña. Participación de NNA: los letreros fueron ideados, diseñados y descritos por ellos. La campaña sirvió para darle mayor cohesión al grupo y parece ser que eso motivó mayor autonomía. Los letreros, el nombre y el logo habían sido propuestas -ahora síinfantiles. Los adultos servimos de transcriptores para las frases de los letreros.

Últimas semanas: queríamos dejar los letreros permanentemente en las calles del tianguis. No obstante, resultaba poco viable por las condiciones de las calles y la fragilidad de los letreros. Entonces, junto con los niños, se acordó hacer de nuevo otra exposición con todo lo que se había realizado hasta la fecha. La invitación a la exposición fue hecha oralmente, a través de los gritos de los niños y de tamborazos y silbatazos, vista por todo aquel que pasaba frente al puesto. Varios adultos se detenían a leer las frases de los carteles y volteaban a ver a los Niños del Tianguis. Participación de NNA: tuvimos que intervenir para comentar los riesgos de dejar los letreros a la intemperie, ya que queríamos evitar que su 
trabajo se dañara o durara muy poco. Con esto, prefirieron hacer la exposición. La manera de invitar se dio espontáneamente.

Las últimas semanas fueron particularmente intensas para los dos integrantes del equipo de investigación. Es necesario mencionar que teníamos muy cerca la fecha de entrega de la investigación y poco tiempo antes habíamos sufrido un secuestro exprés en esa zona. Ambas situaciones (más la segunda que la primera) nos tenían bastante agotados. Compartimos con los niños nuestra intención de tomarnos unas vacaciones. "Ah, sí, qué bueno, porque yo también me voy a ir de vacaciones estos dos días" (dijo uno refiriéndose a dos semanas).

La inseguridad y la violencia que habíamos vivido en el secuestro exprés tuvo un papel importante en la serie de decisiones que fuimos tomando. Debido a que ambos investigadores vivíamos por la zona, decidimos mudarnos, buscando una mejor calidad de vida. Nos mudamos a otro estado, a la Ciudad de México. Tuvimos que conseguir más fuentes de ingresos y entonces trabajar los domingos. Conforme todo esto iba sucediendo, fuimos platicando con los niños; les compartíamos nuestro sentir, así como ellos el suyo. Les dijimos que por el momento tendríamos que ponerle pausa al puesto (así le llamaban), pero que no dejaríamos de ir. En ese momento hicimos un cierre e intercambiamos lo que habíamos hecho, les dijimos que lo que habían logrado y las amistades que habían surgido iban más allá del puesto. Hasta la fecha los seguimos visitando; a veces vemos a unos, a veces a otros. Siempre nos asombramos y nos regalamos abrazos. Nos han llegado a hacer partícipes de sus vidas mandándonos fotos de la confirmación de una de ellos.

\section{Discusión de los resultados}

\section{Discusión de los resultados de la participación infantil}

En primer lugar, se pueden discutir los resultados dentro del ámbito psicológico: mayor confianza, autoestima, cambios en el comportamiento y rendimiento escolar (los que ya asistían a la escuela), redes infantiles basadas en la amistad. No contamos con mediciones rigurosas puesto que no era el objetivo de la investigación: se percibió al valorar más sus dibujos, al desarrollar una manera más asertiva de resolver sus propios conflictos. La grupalidad dio paso a una sensación de cohesión y protección fuera del núcleo familiar y privado.

En segundo lugar, un resultado que sabíamos en la teoría mas no en la práctica: la participación -toda, sí, pero específicamente la infantil- es un proceso y cada uno debe ser 
único. Por lo tanto, las herramientas metodológicas y teóricas deben saber usarse de acuerdo con cada situación. Una participación apresurada, violentada o condicionada no es una participación. Los niños y niñas participaron una vez que sintieron que se les daba la importancia que ellos querían y una participación con cierto grado de autonomía requirió alrededor de cinco meses de trabajo con ellos. Aunque pudiéramos pensar que su corta edad facilitaría la participación (por los presupuestos de que tuvieran poca inhibición), no resultó ser tan evidente. La palabra no es la única participante; las miradas, los gestos, los silencios, las sonrisas, las caricias, las respuestas corporales cuentan mucho.

Desde la perspectiva de lenguajes y visiones diferentes, podríamos poner en discusión un sesgo importante que es el adultocentrismo y es indispensable cuestionarnos el desarrollo de esta investigación y del taller. Para empezar, dentro de nuestra iniciativa de crear un Consejo de participación ciudadana infantil, vislumbrábamos objetivos en el espacio público. Sin embargo, por un lado, los niños no necesitaban de un consejo. Ellos ya estaban incidiendo y participando, modificando sus vidas y las de su entorno. Niños de cinco, seis, siete años se organizaron y dieron lugar a sus necesidades y voluntades más urgentes e inmediatas. ¿Quizás el consejo lo necesitábamos nosotros para aminorar la carga y la inestabilidad del tianguis, del caos, de la inseguridad que vivimos como adultos?

Eso nos hace reflexionar acerca de las vicisitudes de la participación y la escala de Hart. La manipulación adulta puede llegar a suceder incluso suponiendo la 'entera' consciencia y la aspiración al grado más elevado de participación. El haber llegado con el supuesto de que había algo que cambiar en esa zona, en el espacio público, el haber cambiado la sede del taller (procurando su protección, pero sin consultarlo con ellos antes) son algunos de los momentos que podrían ejemplificar la dificultad. Se requiere un proceso de deconstrucción, cuestionamientos a cada paso del proyecto y un aprendizaje constante de ambas partes. El tiempo es un factor importante: parecería que mientras más tiempo se trabaje en ello, mejores serán los resultados. Uno de los aspectos que podría aportar a la discusión puede ser cuestionarse acerca de los límites de la propuesta (de actividades, intervenciones e incluso cuestionamientos) por parte de los adultos y los de una posible manipulación -hasta cierto punto inconsciente, puesto que se hace desde nuestro lugar de poder de adultos: ¿hasta qué punto el proponer puede ser parte del proceso esperado y cuándo comenzaría a ser una imposición velada? Por supuesto que un Consejo facilitaría la toma de decisiones más incluyentes y responsables con la niñez. Es seguro que es una obligación del gobierno. Pero los niños vieron otras vías y tenían otras necesidades probablemente más urgentes. En vez de incidir para mejorar el espacio público, decidieron visibilizar lo privado en lo público. A través de los carteles, en su campaña por el buen trato, 
estaban hablando no solo de la violencia en el tianguis (de hecho, ninguna frase hizo referencia al tianguis per se), sino y, sobre todo, a la vivida en casa.

En este punto, me gustaría preguntarme: ¿hasta dónde llegó su capacidad de agencia? Si contemplamos la agencia como la capacidad de una persona de actuar y cambiar cosas, entornos o situaciones según su voluntad y decisión, tal vez se puede discutir que el objetivo principal era hacer público lo privado incidiendo en lo primero y ese objetivo pareció alcanzarse. Vayamos más a fondo: ¿era ése el objetivo de los niños? Nuestra interpretación de su lenguaje artístico y de sus frases nos llevó a pensarlo, pero sería pertinente preguntarse si lo veían como objetivo o solo era el principio, el camino o si con el tiempo sería uno distinto. Pero ¿generó un cambio en el origen -es decir, en las violencias vividas en lo privado? ¿Ese cambio fue duradero? No tenemos las herramientas para afirmarlo y nos atrevemos a suponer que el cambio fue de corto alcance en ese aspecto puesto que se requeriría más tiempo y distintas metodologías. Abarcaría no solo a los niños sino a su entorno más inmediato: a la familia. Por un lado, la comunidad fue involucrándose (al donar material, apartar espacio, proponer lugares) pero no estamos seguros de que la familia llegara a un nivel de compromiso tal como para cambiar dinámicas familiares. Podría también haber detonado situaciones que pusieran en riesgo a los niños. ¿Cómo lidiar con una agencia tan poderosa que también incomoda y puede vulnerar a su vez? El gobierno, por su parte, ha querido incidir en lo privado a través de políticas públicas que no siempre son eficientes. Los cambios de gobierno pueden alterar la continuidad de cualquier cambio que se pueda generar.

La idea del Consejo de Participación Ciudadana Infantil tenía en la mira el apoyo del gobierno sin afán de pertenecer a ningún partido político. Queríamos solicitar los medios y las herramientas para poder garantizar un desarrollo duradero y, de ser posible, permanente. Después de haber trabajado con los niños y en esa comunidad en particular, dudamos de que el gobierno pueda brindar constancia, seriedad y protección. ¿Cómo pensar entonces en una agencia infantil realmente poderosa y protegida?

La educación (mucho más práctica que teórica, como en el caso de nuestro taller) en los derechos de los niños es un punto esencial. Significa que existe un marco legal que avala y exige la aplicación de los mismos. De esta forma quedaría en los adultos la responsabilidad de garantizar y proteger sus derechos. Pero esa garantía, aún adultocéntrica, no lo es todo. El concepto de respuesta/reacción a las diferencias de Wall (2011) aporta una posible respuesta a las carencias gubernamentales, así como a las problemáticas del corto alcance de una agencia infantil manipulada (en ambas acepciones) o amenazada por adultos. No solo a eso, sino a la falta de poder de las minorías. El poder estaría en la diferencia y la democracia radicaría en la respuesta a esas diferencias. Adoptar este concepto en una comunidad, enfocados a la participación infantil a muy largo plazo, sería una propuesta bastante 
interesante en un país en el que las instituciones jurídicas y gubernamentales han perdido bastante credibilidad, permitiendo que los abusos (en lo público y en lo privado) se realicen, muchas veces, sabiendo que reinará la impunidad. Podríamos, tal vez, comenzar a hablar de un verdadero empoderamiento infantil.

\section{En los ámbitos de la investigación}

Desprenderse del rol de investigador no siempre resulta sencillo. Este tipo de intervenciones y talleres con niños requieren un alto despojamiento del mundo adulto a la vez que exigen una gran capacidad de análisis y cuestionamiento constante acerca de los motivos, las maneras y los actores de la participación. Trabajar con la agencia infantil, procurarla, es un proceso de deconstrucción, a veces de contradicciones (¿dejar participar en total autonomía o proteger en el mejor interés del niño?) y de cuestionamientos. Los alcances y los límites de cada participación infantil son únicos, pero no contemplarlos puede desembocar en decisiones o acciones riesgosas.

La escucha atenta y respetuosa de las participaciones infantiles involucra un componente esencial que parece escasear en los tratados y manuales. Es un proceso también afectivo. Los lazos que se crean son fuertes e implican un compromiso e involucramiento intensos. Es cierto que la presencia del investigador influye en el campo, pero poco se habla de lo mucho que influye el campo, en este caso, los niños, en el investigador. Se requiere de una ética rigurosa y no resulta nada fácil sopesar siempre las cuestiones éticas, los lazos afectivos, la seguridad de absolutamente todos los participantes y los objetivos de la investigación.

El financiamiento y el soporte institucional también son importantes. Si se hubiera contado con algún tipo de financiamiento tal vez hubiera sido más factible continuar con el proyecto. Sin duda alguna, se necesita un soporte mucho más fuerte que la voluntad de dos jóvenes investigadores para poder formalizar ante instancias gubernamentales. Debido a la situación crítica de violencia del país y del Estado de México, también sería indispensable regresar con más recursos tanto monetarios, como académicos, psíquicos y humanos. Definitivamente es posible y es viable.

\section{Conclusiones}

La participación infantil es un eje rector de los derechos de NNA. Fuente fructífera de aprendizajes y de beneficios, puede ser un vehículo hacia la democracia, el aprendizaje de la ciudadanía, la mejora de las redes sociales y comunitarias y el incremento en la calidad de 
vida de los niños. Aun así, el ser declarados sujetos de derechos no forzosamente indica que su estatus social evolucione; lo público y lo privado deben trabajar por un bien común. El paso de ser sujetos de derechos a ser sujetos con capacidad de agencia y ser partícipes en la escena social implica cuestionarnos acerca de los mismos conceptos de agencia infantil, poder, democracia y, por supuesto, participación infantil, sabiendo que esta última nunca es unilateral, inequívoca, única ni sencilla.

\section{Referencias bibliográficas}

Breviglieri, M. (2014). La vie publique de l'enfant. Participations, 9(2), 97-123. doi:10.3917/parti.009.0097.

Contreras, R. (2002). La Investigación Acción Participativa (IAP): revisando sus metodologías y sus potencialidades, en J. Durston y F. Miranda (Comp.). Experiencias y metodologías de la investigación participativa. (pp.: 9-17). Chile: Naciones Unidas.

Corona, Y., Gáal, F. (2009). Estrategias Participativas para Niños: Algunos aportes para escuchar a los niños y realizar consultas infantiles. México: UAM-X.

Corona, Y., Gómez, M., Zanabria, M. (coordinadoras). (2013). Explorando caminos de participación infantil y juvenil. Universidad Autónoma Metropolitana (UAM). Red por los Derechos de la Infancia en México (REDIM). Universidad de Valencia. México.

Del Río, N., Corona, Y., Gülgonen, T., Vasconcelos, M. (2014). Educación, Juego y Actividades Culturales. En Garantía de derechos de niñas, niños y adolescentes. Miradas al Estado Mexicano. (pp.: 76-85). Anexo: Informe Alternativo al cuarto y quinto informe consolidado sobre el cumplimiento de los derechos del niño en México 2006 - 2013. Versión Extendida. México: Alianza por los Derechos de Niñas, Niños y Adolescentes. Disponible en: http://www.alianzamx.org.mx/publicaciones/Informe\%20Alternativo\%204to_5to_ CDN_Final.pdf

Doek, J.E. (2007). The CRC General Principles. En 18 Candles. The Convention on the Rights of the Child Reaches Majority. (pp.: 31-38). Suiza: Institut international des droits de l'enfant (IDE).

González Contró, M. (2011). Los derechos de niños, niñas y adolescentes en México a 20 años de la Convención sobre los Derechos del Niño. México: Porrúa, IIJ-UNAM, Save the Children. 
Hart, R. (1993). La Participación de los Niños. De la Participación Simbólica a la Participación Auténtica. Ensayos Innocenti, no. 4. Nueva York: UNICEF, 1-47.

Hart, R., Wridt, P., Giusti, D. (2011). Ciudades y Comunidades Amigas de la Infancia (CAI). Una investigación de campo de las herramientas de estudio para la evaluación participativa de las condiciones comunitarias para los niños. Cuestionario de autoevaluación de Ciudades Amigas de la Infancia para niños y niñas.

Lansdown, G. (2001). Promoviendo la participación de los niños en la toma de decisiones democráticas. En Promoting children's participation in democratic decisionmaking. Florencia: Instituto Innocenti de investigación de UNICEF.

Lansdown, G. (2005). ¿Me haces caso? El derecho de los niños a participar en las decisiones que los afectan. Cuadernos sobre Desarrollo Infantil Temprano № 36s. La Haya: Fundación Bernard van Leer.

Lansdown, G. (2011). Every child's right to be heard. A resource guide on the UN Committee on the Rights of the Child General Comment no 12. Reino Unido: Save the Children UK.

Lee, Y. (2007). 18 Candles. En 18 Candles. The Convention on the Rights of the Child Reaches Majority. Suiza: Institut international des droits de l'enfant (IDE).

Pinheiro de Almeida, M. T. (2012). El jugar de los niños en espacios públicos, Tesis Doctoral, Barcelona: Universidad de Barcelona, disponible en: http://www.tdx.cat/bitstream/handle/10803/96172/02.MTPA_TEXTO_CASTELLA NO.pdf?sequence $=2$

Sahuí, A. (2002). Hannah Arendt: Espacio público y juicio reflexivo. En Signos filosóficos, núm. 8. Campeche: Universidad Autónoma de Campeche, 241-263

Valera, S. (1999). Espacio privado, espacio público: Dialécticas urbanas y construcción de significados, Tres al Cuarto, 6, Barcelona: Universidad de Barcelona, pp. 22-24, disponible en http://www.ub.edu/escult/doctorat/html/lecturas/tresal.pdf

Wall, John. (2011). Can Democracy Represent Children? Toward a politics of difference. Childhood, 19(1), 86-100.

\section{Otras fuentes consultadas}

Cantwell, N. Plática en plataforma Coursera. CRC General Principles. Disponible en: https://www.coursera.org/learn/childrens-rights/lecture/Zsvqi/1-2bis-crc-generalprinciples 
Gobierno de la República (2014). Programa Nacional para la Prevención de la Violencia y la Delincuencia 2014-2018. Diario Oficial de la Nación. Disponible en http://www.dof.gob.mx/nota_detalle.php?codigo=5343087\&fecha=30/04/2014

Ley General de los Derechos de Niñas, Niños y Adolescentes. (2014). México. Disponible en http://www.dof.gob.mx/nota_detalle.php?codigo=5374143\&fecha=04/12/2014

Pourailly, M.C. (2015). Espacio Público y Formación Integral en La Infancia: Taller de formación en valores comunitarios y medioambientales para niños en edad preescolar a partir del espacio público como entorno de aprendizaje. Disponible en:

http://desarrollourbanoyterritorial.duot.upc.edu/sites/default/files/M.Pourailly_MD UT\%202014.pdf

UNICEF - Centro de Derechos Humanos de las Naciones Unidas. (1989). Convención sobre los Derechos del Niño. Nueva York. Disponible en: http://www.un.org/es/events/childrenday/pdf/derechos.pdf 